\title{
2-Methylfuran: A Bio-Derived Octane Booster for Spark-Ignition Engines
}

\author{
Eshan Singh $^{1 *}$, Vijai Shankar Bhavani Shankar ${ }^{1}$, Rupali Tripathi ${ }^{2}$,
}

\author{
Heinz Pitsch ${ }^{2}$, S. Mani Sarathy ${ }^{*}$
}

1. Clean Combustion Research Center, King Abdullah University of Science and Technology, Thuwal 23955-6900, Saudi Arabia

2. Institute for Combustion Technology, RWTH Aachen University, 52056 Aachen, Germany

\section{Abstract}

The efficiency of spark-ignition engines is limited by the phenomenon of knock, which is caused by auto-ignition of the fuel-air mixture ahead of the spark-initiated flame front. The resistance of a fuel to knock is quantified by its octane index; therefore, increasing the octane index of a spark-ignition engine fuel increases the efficiency of the respective engine. However, raising the octane index of gasoline increases the refining costs, as well as the energy consumption during production. The use of alternative fuels with synergistic blending effects presents an attractive option for improving octane index. In this work, the octane enhancing potential of 2-methylfuran (2-MF), a next-generation biofuel, has been examined and compared to other high-octane components (i.e., ethanol and toluene). A primary reference fuel with an octane index of 60 (PRF60) was chosen as the base fuel since it closely represents refinery naphtha streams, which are used as gasoline blend stocks. Initial screening of the fuels was done in an ignition quality tester (IQT). The PRF60/2-MF (80/20 v/v\%) blend exhibited longer ignition delay times compared to PRF60/ethanol (80/20 v/v\%) blend and PRF60/toluene (80/20 v/v\%) blend, even though pure 2-MF is more reactive than both ethanol and toluene. The mixtures were also tested 
23 in a cooperative fuels research (CFR) engine under research octane number and motor octane

24 number like conditions. The PRF60/2-MF blend again possesses a higher octane index than other

25 blending components. A detailed chemical kinetic analysis was performed to understand the

26 synergetic blending effect of 2-MF, using a well-validated PRF/2-MF kinetic model. Kinetic

27 analysis revealed superior suppression of low-temperature chemistry with the addition of 2-MF.

28 The results from simulations were further confirmed by homogeneous charge compression

29 ignition engine experiments, which established its superior low-temperature heat release (LTHR)

30 suppression compared to ethanol, resulting in better blending octane numbers. This work

31 explores and provides a chemically sound explanation for the potential of 2-MF as an octane

32 enhancer.

33 Introduction

34 Engine knock has always been a significant bottleneck in improving the efficiency of spark35 ignition (SI) engines [1]. The resistance of a fuel to auto-ignition, and therefore knock, is 36 quantified by two octane numbers, viz., research octane number (RON) and motor octane 37 number (MON). The octane numbers are measured according to ASTM 2699 (RON) [2] and

39 using a scale with $n$-heptane as the lower boundary ( $\mathrm{ON}=0$, highly prone to knocking) and iso40 octane as the upper boundary ( $\mathrm{ON}=100$, less prone to knocking) [4].

41 Fuel specifications in many countries have established minimum octane ratings for regular and

42 premium gasoline fuels. Isomerization and reformation processes synthesize the hydrocarbon

43 species in the fuel that increase its octane index to meet the specifications. The incorporation of

44 these processes results in additional capital and operational expenses making gasoline more 45 expensive to the end user. The mandate to blend renewable fuels in gasoline, especially ethanol, 
46 has reduced the burden on some large refiners. The synergistic blending effect of ethanol

47 especially at low volume ratios dramatically increases the octane rating of gasoline [8] and aids

48 in the reduction of cost of production of refinery gasoline streams. Ethanol's resistance to auto-

49 ignition is, at least for direct-injected engines, due to its charge cooling effect, driven by the high

50 latent heat of vaporization, and its radical scavenging nature, which suppresses the $\mathrm{OH}$ formation

51 responsible for chain branching reactions leading to auto-ignition $[5,6]$.

52 The use of ethanol as a biofuel has garnered much criticism. Ethanol production from food crops

53 has been estimated to have a thermodynamically net negative energy flow [7]. Several studies [8,

54 9] have shown that increased production of crops for biofuel production has a detrimental effect

55 on land use. Biofuels from biomass, cultivated on lands unsuited for agriculture or agricultural

56 waste, are an attractive proposition. This biomass feedstock would be primarily lignocellulosic,

57 and a variety of chemical compounds could be extracted from it for use as fuel. Furans are one of

58 the classes of compounds that could be produced from lignocellulosic biomass [10]. They have

59 generated research interest due to their higher heating value being comparable to commercial

60 gasoline on a volumetric basis and superior anti-knock properties. Improved production methods

61 of furanic compounds have also been realized in 2009 [11-17]. Researchers at the University of

62 Wisconsin-Madison accomplished the conversion of hexose and other sugars to 2-MF through

63 hydroxymethylfurfural (HMF), formed by the elimination of three oxygen atoms, which further

64 undergoes hydrogenolysis to produce 2-MF [16]. Zhao et al. improved the method, thereby 65 dramatically reducing production costs [17]. 2,5-Dimethylfuran and 2-Methylfuran have both 66 been tested for their benefits in spark ignited engines [11-14, 18].

67 The potential of 2-MF as a biofuel derives from the possibility of its production from 68 lignocellulosic biomass [19]. A select number of physical properties and octane numbers of 2- 
MF are compared with that of ethanol, toluene, and 2,5-DMF in Table 1. Although the furanic

70 molecules (2,5-DMF and 2-MF) show similar behavior, 2-MF has some advantages, such as a

71 lower boiling point than 2,5-DMF and ethanol, hence better cold-start performance. The lower

72 flash point of 2-MF also means safer handling, storage, and transport. The greater enthalpy of

73 vaporization of 2-MF compared to 2,5-DMF would result in a better charge cooling effect

74 increasing charge density and power output [14]. The significantly larger viscosity and density of

75 2-MF compared to ethanol would impede the fuel flow from the injector nozzle, resulting in

76 lower droplet velocity and poor spray break-up. However, lower boiling point, accompanied with

77 lower latent heat of vaporization, results in improved evaporation $[20,21]$. Higher viscosity and

78 poorer spray break-up would also cause higher particulate emissions [22]. The faster flame speed

79 of 2-MF compared to 2,5-DMF provides high knock resistance and peak pressure rise rates [23].

80 Combustion duration is considerably faster than ethanol, 2,5-DMF, and gasoline [14]. The use of

81 2-MF resulted in high oxygen content and combustion temperature, as well as lower hydrocarbon

82 emissions and increased $\mathrm{NO}_{\mathrm{x}}$ emissions, compared to 2,5-DMF and gasoline [14, 20]. The

83 indicated thermal efficiency was found to be higher than gasoline and 2,5-DMF over the entire

84 load range $[14,20]$. 2-MF also exhibited more robust combustion under stoichiometric as well as

85 lean operation making it a strong candidate for homogenous lean operation engines, another

86 future engine technology. The cycle-to-cycle variations were also the lowest for 2-MF when

87 compared to ethanol and 2,5-DMF. Combustion and indicated thermal efficiency were lower

88 than ethanol, and higher than DMF, over the load range. Indicated specific emissions of NOx

89 were observed to be higher than either ethanol or DMF. Indicated specific HC emissions were

90 higher than ethanol, and lower than DMF. Indicated specific CO emissions were the highest,

91 compared to DMF and ethanol, at lower loads, while they were lower than DMF at higher load 
92 operation [14]. Engine studies in port fuel injected (PFI) SI engines yielded higher 93 thermodynamic efficiencies and 30\% lower indicated specific fuel consumption than ethanol. 94 Although they have similar molecular structure, 2-MF and 2,5-DMF have disparate combustion 95 characteristics, marked by higher burn rate and superior knock resistance of 2-MF.

\begin{tabular}{llllll}
\hline Properties & 2-MF & Ethanol & Toluene & $2,5-\mathrm{DMF}$ & Ref. \\
\hline Density $\left(\mathrm{kg} / \mathrm{m}^{3}\right)$ & 913.2 & 790.9 & 867 & 889.7 & {$[23]$} \\
Viscosity $\left(\mathrm{mPa}^{*} \mathrm{~s}\right)$ & 4.00 & 1.08 & 0.59 & 0.65 & {$[20]$} \\
Boiling Point $\left({ }^{\circ} \mathrm{C}\right)$ & 64 & 78 & 111 & 92 & {$[20]$} \\
Enthalpy of Vaporization $(\mathrm{kJ} / \mathrm{kg})$ & 358 & 912 & 413 & 332 & {$[20]$} \\
Flash Point $\left({ }^{\circ} \mathrm{C}\right)$ & -22 & 16.6 & 6 & 16 & {$[14]$} \\
Stoichiometric & 10.08 & 8.98 & 13.43 & 10.72 & \\
Lower Heating Value $(\mathrm{MJ} / \mathrm{l})$ & 27.63 & 21.09 & 35.19 & 32.89 & {$[20]$} \\
RON & $\sim 103$ & $\sim 108$ & $\sim 120$ & $\sim 101$ & {$[14]$} \\
MON & 86 & 89.7 & $\sim 100$ & 88.1 & {$[14]$} \\
Sensitivity & 17 & 18.3 & 20 & 12.9 & {$[14$,} \\
& & & & & $24]$ \\
\hline
\end{tabular}

98 Kalghatgi [25-27] proposed the use of octane index (OI), a better representation of anti-knock 99 characteristic for modern engines. Equation (1) represents the OI as,

$$
O I=R O N-K * S
$$


$\mathrm{S}$ refers to the octane sensitivity, and it is the difference between RON and MON of a fuel. K is an empirical constant depending on the engine and the operating condition, and independent of the fuel. The superior performance of OI in predicting fuel behavior compared to the RON-MON metric was demonstrated in Ref [28]. $\mathrm{K}$ values of modern turbocharged SI engines are exceedingly negative at high load points. The implication being that a fuel with high RON and S (lower MON) will have a greater OI at these operating points. The $\mathrm{K}$ of RON and MON tests are, by definition, 0 and 1, respectively. Modern engines tend to be turbocharged, direct injected, and operate at lower engine speeds, which leads to lower in-cylinder temperatures than RON and MON test conditions. The continuing trend of engine design towards even more negative $\mathrm{K}$ values is driving research into fuel sensitivity and understanding the chemical kinetics dictating it [29-34]. In this regard, 2-MF could be a very interesting future fuel, as it has a high $\mathrm{S}$ value (mostly attributed to chemical kinetic pathways), coupled with high RON.

Several compounds raise both the RON and $\mathrm{S}$ of a base fuel when blended. Blending octane number $(\mathrm{BON})$ is a metric that quantifies the effect of blending on octane number. $\mathrm{BON}$ is the linearly-extrapolated octane number of a pure compound from the octane number of the blend [35]. A positive deviation of $\mathrm{BON}$ from the measured $\mathrm{RON}$ of a compound indicates a synergistic blending effect. Lovell [36] determined that 2-MF has a BON of 209 at RON-like condition and 180 at MON-like condition when blended in $20 \%$ volume with the primary reference fuel having octane number of 60 (PRF60). The RON and MON of pure 2-MF were found to be close to 100 and 86, respectively. In contrast, the BON of toluene was 124 (at RONlike conditions) and 112 (at MON-like conditions), even though its measured RON and MON were 120 and 100, respectively. Recent results by Tiunov et al. showed maximum blending octane number of 2-MF and 2,5-DMF blended with toluene primary reference fuel TPRF80 at 
$12310 \% \mathrm{v} / \mathrm{v}$ blends. An increase in the $\mathrm{S}$ value with a higher furanic component in the fuel was also 124 reported [37].

125 This work experimentally reaffirms the exceptional synergistic blending effect of 2-MF by 126 measuring and comparing its blending octane number (BON) with ethanol and toluene. The 127 chemical kinetics leading to the observed results is also explored using a well-validated ignition 128 kinetic model for PRF60/2-MF [38].

\section{Methodology:}

\section{Experimental (IQT tests)}

131 The baseline fuel used was PRF60, which is a mixture of $40 \% n$-heptane and $60 \%$ iso-octane 132 (v/v). PRF60 is representative of blendstock into which high octane components are blended. 133 PRF60 has also been used as a base stock for finding blending octane number (BON) in ASTM 134 D-908 [36]. The purity of the chemicals was $>99 \%$. 2-MF was mixed in 5\%, 10\%, and 20\% (v/v) 135 in PRF60. All three 2-MF mixtures were compared to respective mixtures of ethanol or toluene 136 in PRF60. The proceeding nomenclature uses PRF60, followed by MF for 2-MF, E for ethanol 137 and $\mathrm{T}$, indicating toluene, followed by their volume concentration in the mixture. Initial 138 screening of the mixtures was performed in an ignition quality tester (IQT). The details of the 139 experimental apparatus are provided in Ref [39]. The experiments were performed according to 140 standard ASTM D6890 [40]. The pressure inside of the constant volume chamber was 141 maintained around 25 bar and the fuel was injected with a pressure of 150 bar. The temperature 142 of the air was maintained so that ignition delay of $n$-heptane was at the specified value of $3.78( \pm$ 143 0.03) milliseconds. A gradient method was used to determine the start of ignition. The point of 144 interaction of two tangential lines, one at the pressure recovery point, the point where chamber 
145 pressure reaches back to initial pressure after evaporative cooling and the second at the

146 maximum slope of the pressure-time curve, is considered to be the start of ignition. The time

147 between the start of injection, marked by needle lift, and start of ignition is the ignition delay

148 time (IDT). Other methods used for determining the IDT, and their implications on the final IDT

149 value, have been discussed in Ref [39]. The ASTM standard also provides for the conversion of

150 IDT to derived cetane number (DCN), according to the equations

$$
\begin{gathered}
D C N=4.46+\left(\frac{186.6}{I D T(m s)}\right) \\
D C N=83.99\left[\left(I D T(m s)-1.512^{-0.658}\right)\right]+3.547
\end{gathered}
$$

151 Equation (2) is applied for IDT between $3.1 \mathrm{~ms}$ to $6.5 \mathrm{~ms}$. Equation (3) is for IDT greater than

$1526.6 \mathrm{~ms}$. An empirical relation between the IDT and RON was proposed in Ref [41] as elucidated 153 in equation (4),

$$
R O N=-293\left(\frac{D C N}{100}\right)^{2}-52\left(\frac{D C N}{100}\right)+114.1
$$

154 The IQT used in the study has been modified to accommodate fuels with longer IDT. The 155 modifications have resulted in greater standard deviations of the measured results compared to $156 \operatorname{Ref}[41]$

\section{Experimental (KLSA tests)}

158 The knock-limited spark advance (KLSA) of the mixtures were determined in RON-like and 159 MON-like conditions. The geometrical and operating specifications of the cooperative fuels 160 research (CFR) engine used in the experiments are listed in Table 2. The CFR was modified by 161 replacing the carburetor with a port fuel injector. The air temperature was measured and 
162 controlled in these tests, as opposed fuel-air charge temperature in MON tests. Therefore, in 163 subsequent discussions, the tests are referred to as RON-like and MON-like.

\begin{tabular}{|c|c|c|}
\hline & RON-like & MON-like \\
\hline Engine Type & \multicolumn{2}{|c|}{ Modified CFR F-1/F-2 } \\
\hline Number of Cylinders & \multicolumn{2}{|c|}{1} \\
\hline Bore $(\mathrm{mm})$ & \multicolumn{2}{|c|}{82.5} \\
\hline Stroke (mm) & \multicolumn{2}{|c|}{114} \\
\hline $\begin{array}{l}\text { Connecting rod Length } \\
\qquad(\mathrm{mm})\end{array}$ & \multicolumn{2}{|c|}{254} \\
\hline Fuel Injection & \multicolumn{2}{|c|}{ Port fuel injection } \\
\hline Equivalence Ratio & \multicolumn{2}{|c|}{1.0} \\
\hline Compression Ratio & 5.5 & 5 \\
\hline Speed & 600 & 900 \\
\hline Intake Temperature $\left({ }^{\circ} \mathrm{C}\right)$ & 52 & 149 \\
\hline
\end{tabular}

165 The RON-like tests were performed with an intake air temperature of $52{ }^{\circ} \mathrm{C}$ and an engine speed 166 of $600 \mathrm{rpm}$. The compression ratio of 5.5 was utilised as negligible knock intensity was recorded 167 for the base fuel with the spark timing at $+4^{\circ} \mathrm{CA}$ after top dead centre (aTDC). The spark timing 168 was advanced and knock intensity (in the form of knock peak value), was recorded for 180 169 cycles. The average values of knock peak with standard deviations are reported. For KLSA tests 170 at MON-like conditions, the intake air temperature and the engine speed were increased to $149^{\circ} \mathrm{C}$ 171 and $900 \mathrm{rpm}$, respectively. The compression ratio was lowered to 5 for the reason stated above. 
173 The chemical kinetic mechanism used for simulating the ignition of the fuel mixture studied in 174 this work is a combination of two validated models for primary reference fuel (PRF) [42] and 2175 MF [38]. The details of the PRF mechanism is fully detailed in Atef et al. [42] and has been 176 utilized here without modification. The mechanism contains a well-validated $\mathrm{C}_{0}-\mathrm{C}_{6}$ base 177 chemistry along with detailed oxidation pathways of $n$-heptane and iso-octane [42]. A detailed 178 model of 2-MF covering both low and high temperature reaction pathways was adopted from the 179 work of Tripathi et al. [38] and added together with the PRF mechanism. The high-temperature 180 specific 2-MF chemistry in their model [38] was adopted from Somers et al. [43], and 181 extensively revised, based on more recent kinetic studies [44, 45]. The 2-MF mechanism 182 considered, incorporates several updates to older 2-MF mechanisms in the literature. The most 183 significant alterations include the addition of $\mathrm{O}_{2}$ to 2-MF fuel radical, the alkene specific low184 temperature pathways of 2-MF, and co-oxidation reactions between 2-MF and $n$-heptane. The 185 incorporated 2-MF mechanism was extensively validated against ignition delay times, laminar 186 flame speeds, and species profiles in various experimental setups [38]. The results of compilation 187 have been added to the supplementary material.

188 Zero-dimensional chemical kinetics simulations were performed using the homogenous batch 189 reactor model in Chemkin Pro [46]. The program solves energy equations at constant volume to 190 determine energy released, pressure, temperature, and species fractions as a function of time. 191 Ignition is defined as the point of maximum slope of the temperature-time curve. If there are 192 multiple local maxima, as in the case of two-stage ignition process, the latest value was 193 considered as the time of ignition. The ignition delay times for mixtures of equivalence ratio 1 , 194 from $650 \mathrm{~K}$ to $950 \mathrm{~K}$ at intervals of $25 \mathrm{~K}$ at a pressure of 20 bar were simulated for PRF 60, 
PRF60MF20, PRF90, and PRF60T20. The conditions of the simulations have been demonstrated to cover the in-cylinder conditions during the octane rating tests [21, 47]. IDT is mostly insensitive to temperatures beyond $950 \mathrm{~K}$ [48-52]. The temperature range covers the negative temperature coefficient (NTC) region. Fuels with a higher S value tend to show low-to-no NTC region and have monotonically increasing IDT with temperatures [53-55]. The time histories of heat release, temperature, and evolution of $\mathrm{OH}, \mathrm{HO}_{2}$ at $750 \mathrm{~K}$ and 25 bar were investigated to the quantify the suppression of low temperature chemistry (LTC) due to different high octane components. The IDT at this condition correlates well with RON.

\section{Experimental (HCCI tests)}

The trends observed were then validated against the homogeneous charge compression ignition (HCCI) experiments, also conducted in the CFR engine. The methodology followed for conducting the experiments was based on HCCI number methodology first proposed in Ref [56], and later used by Waqas et al. to ascertain fuel reactivity at lean homogenous conditions [57]. The HCCI experiments were conducted with an intake temperature of $52^{\circ} \mathrm{C}$, engine speed of 900 rpm and equivalence ratio of 0.3 . The compression ratio was adjusted to phase the CA 50 of the combustion at 3 deg aTDC. The compression ratio required to maintain this combustion phasing provides the HCCI number of the fuel as proposed in Ref [57]. The HCCI number calibration for this experimental apparatus was performed and reported by Waqas et al. The engine was run with base fuel PRF60, and the compression ratio was varied to achieve CA50 of 3 CAD after TDC at $\lambda=3$ ( $\lambda=$ ratio of actual air-fuel ratio to stoichiometric air-fuel ratio). Thereafter, mixtures of PRF60 with ethanol and 2-MF in blend ratios of 5\%, 10\%, 15\%, and 20\% (v/v) were tested. With the addition of octane boosting additives, the compression ratio had to be increased to maintain $\mathrm{CA} 50$ to be $3 \mathrm{CAD}$ after TDC. The compression ratio can be used to give a rating 
218 (HCCI \#3) to the fuels; this is based on the volumetric blend of iso-octane in a mixture of iso-

219 octane and $n$-heptane, required to match the compression ratio of the tested fuel. The correlation

220 developed by Waqas et al. [57] has been updated to include a wider range of PRFs, and

221 therefore, HCCI number. The blending HCCI number can also be ascertained from this, based on

222 linear rating correlation given by:

$$
H C C I_{\text {base }} C_{\text {base }}+\text { BON. } C_{\text {booster }}=H C C I_{\text {mix }} \quad .
$$

223 A comprehensive heat release analysis was performed on the pressure data obtained from the

224 HCCI experiments. The first law of thermodynamics, in conjunction with heat losses from heat

225 transfer to the wall, crevices and blow-by losses, was considered. The analysis was performed

226 separately on each of the 190 cycles at operating conditions mentioned above. The standard

227 deviation of the pressure data was 0.04 bar. The average value of the heat release is reported

228 here. More details on heat release calculations are provided in the Appendix of Ref [5].

\section{Results and Discussion}

$230 \quad$ Ignition Delay Time from IQT:

231 The results from the IQT are tabulated in Table 3. It can be seen that PRF60MF10 is nearly as

232 reactive/unreactive as PRF60T20 and PRF60E20. The surprisingly high BON of 2-MF reported

233 by Lovell [36] is reaffirmed. DCN was obtained from the ignition delay period according to

234 ASTM 6890. Previous researchers have correlated this DCN value with RON, accurate to few

235 points [41]. Relatively simpler IQT tests provide a RON bracket for the blend fuel, not an

236 accurate RON value, as pointed out in [41]. These calculated RON values are plotted in Fig. 1. It

237 can be observed that 2-MF is highly effective at suppressing reactivity of PRF60, even at very

238 low concentrations. It is already known that ethanol (a radical scavenger) has a high BON value, 
239 as it displays synergistic non-linear octane behavior with gasoline [58]. RON values of ethanol

240 blends, however, plateau at 20\% v/v concentration, while 2-MF blends shows a much higher

241 RON value at $20 \% \mathrm{v} / \mathrm{v}$, after closely following RON of ethanol blends at $5 \%$ and $10 \% \mathrm{v} / \mathrm{v}$. Pure

242 2-MF shows inferior resistance to auto-ignition tendency compared to both ethanol and toluene,

243 as measured in IQT (and shown by previous researchers); but in small quantities, it improves the

244 octane quality of PRF60 dramatically.

Table 3: Measured IDT and Calculated DCN.

\begin{tabular}{|c|c|c|c|c|}
\hline Blend & IDT & Std. Dev & DCN & Std. Dev \\
\hline & $\overline{(\mathrm{ms})}$ & IDT & (\#) & $\mathrm{DCN}$ \\
\hline PRF60E5 & 6.66 & 0.14 & 32.13 & 0.58 \\
\hline PRF60E10 & 7.64 & 0.16 & 29.02 & 0.42 \\
\hline PRF60E20 & 7.09 & 0.11 & 30.67 & 0.36 \\
\hline Ethanol & 93.09 & 14.27 & 7.95 & 0.87 \\
\hline PRF60T5 & 6.30 & 0.12 & 34.08 & 0.70 \\
\hline PRF60T10 & 6.52 & 0.16 & 32.66 & 0.83 \\
\hline PRF60T20 & 7.09 & 0.11 & 29.03 & 0.31 \\
\hline Toluene & 213.17 & 9.86 & 6.03 & 0.16 \\
\hline PRF60MF5 & 6.64 & 0.09 & 32.21 & 0.34 \\
\hline PRF60MF10 & 7.64 & 0.11 & 29.03 & 0.31 \\
\hline PRF60MF20 & 10.37 & 0.40 & 23.54 & 0.69 \\
\hline 2-MF & 72.39 & - & 6.84 & 0.96 \\
\hline
\end{tabular}


247 After comparing ignition delay times in IQT, the same mixtures were run on a CFR engine in

248 knock-limited spark timing (KLSA) tests at RON-like and MON-like conditions.

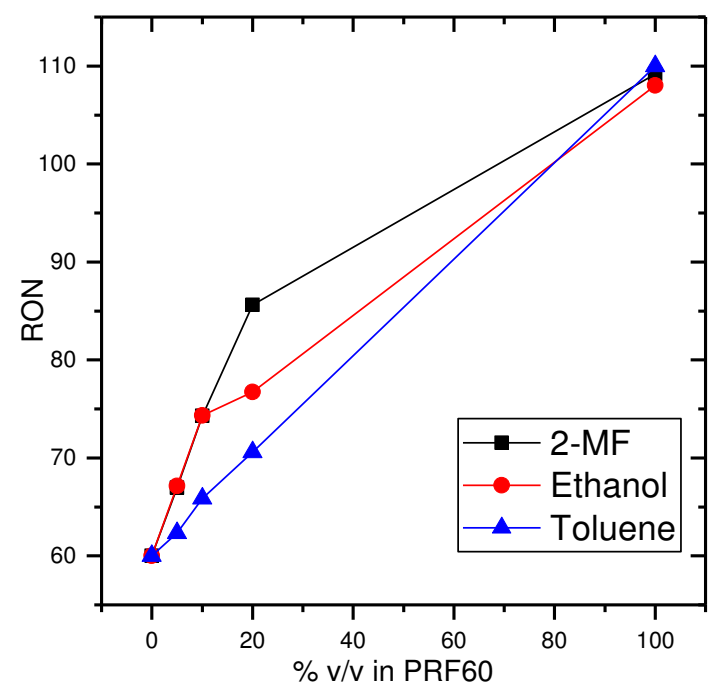

250 Figure 1: Calculated RON values from IQT ignition delay times.

$251 \quad$ Knock limited Spark Advance Tests in CFR:

252 The results of KLSA tests near RON-like conditions are presented in Fig 2. The observations 253 qualitatively compare well with IDT measured in the IQT discussed previously. Knock intensity 254 decreased in the following order: PRF60, PRF60MF5, PRF60E20, PRF60T20, PRF60MF10, and 255 PRF60MF20. The knock suppression characteristics of 10\% 2-MF in PRF60 is better than $20 \%$ 256 of toluene and ethanol in PRF60. Figure 3 shows KLSA test observations for MON-like 257 conditions. 2-MF performs even better in MON-like conditions. The trend was same as in the 258 RON condition, however, the engine was not knock-limited at any spark timing when using $20 \%$ 259 (v/v) 2-MF (considering threshold knock intensity value to be 0.5 bar). 


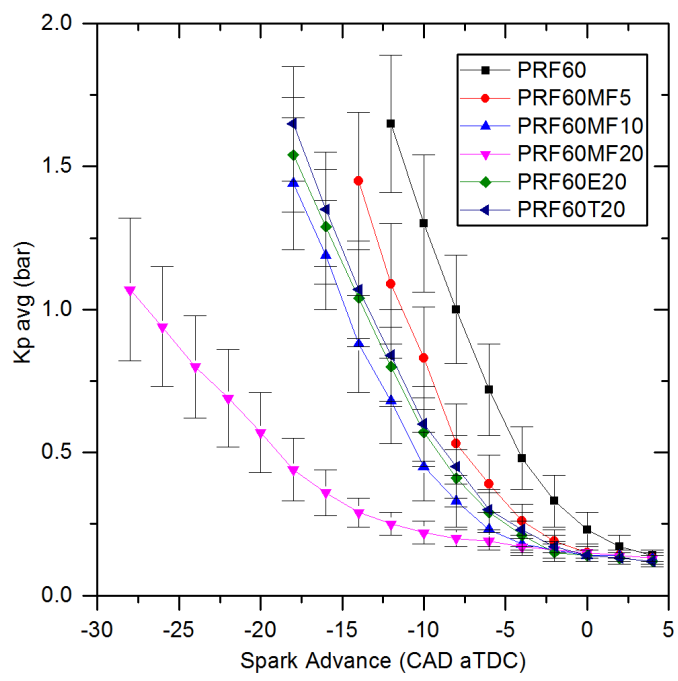

261 Figure 2: KLSA tests performed in RON-like conditions.

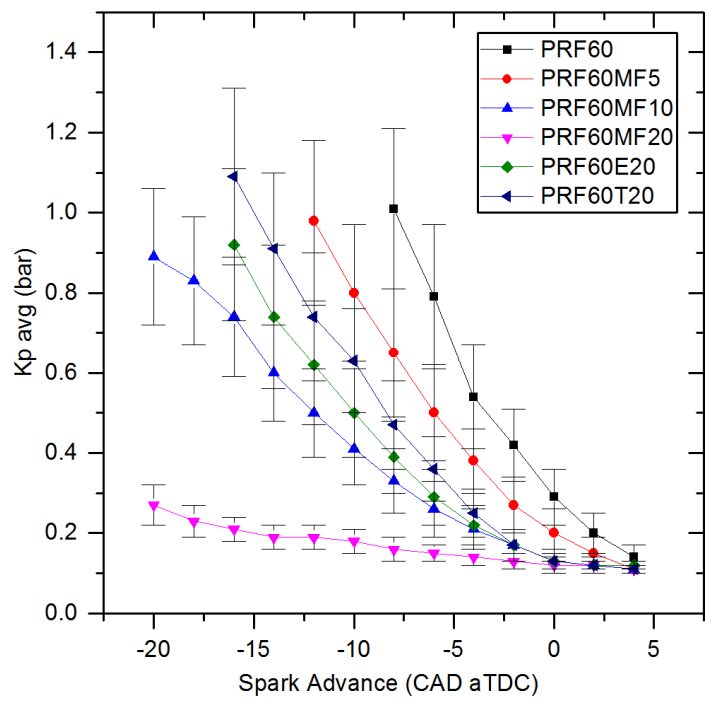

263 Figure 3: KLSA tests performed in MON-like conditions.

Ignition delay calculations:

265 The chemical kinetics supporting the highly effective knock suppression of 2-MF blends was 266 explored using chemical kinetic simulations. Several authors have related the S-value of a fuel 267 with the NTC region observed when plotting IDT versus 1000/T. The simulated IDT for 
268 different mixtures are presented Fig. 4. The two vertical lines refer to temperature corresponding

269 to end gas temperature in RON and MON testing [32]. A highly disparate ignition behavior of

270 PRF60MF20 blend can be observed. 2-MF is found to be very effective in increasing ignition

271 delay time at intermediate and low temperatures, which explains its extremely effective behavior

272 in the KLSA tests above. The addition of 2-MF completely suppressed the LTC reactivity,

273 leading to higher ignition delay times in both RON and MON conditions. This is a result of the

274 high S-value of the fuel, which was captured well in the simulations. In contrast, PRF60 showed

275 pronounced NTC regions. PRF60T20 increased the S-value and the IDT at low- and intermediate

276 temperatures was higher. PRF60MF20 mixture show a higher ignition delay time compared to

277 ethanol and toluene mixtures. The difference is higher at low temperatures because of absence of

278 the LTC chemistry. PRF60MF20, for example, increases monotonically, while the other

279 mixtures show reduced ignition delay times due to the dip in NTC regime.

280 Previous research has shown that IDT at fixed temperature-pressure conditions for a

281 homogenous batch reactor case can replicate the fuel behavior at RON and MON conditions [54,

$28259,60]$. RON is well represented at $750 \mathrm{~K}$ and 25 bar [32]. These conditions are indicative of

283 end-gas conditions on the verge of auto-ignition (or knock). The evolution of reactivity at these

284 conditions in a batch reactor simulations would represent the chemistry of fuel-air mixture in

285 octane tests. The mixtures analyzed earlier were then simulated in a homogenous batch reactor

286 with constant volume. The temporal history of temperature, heat release and the evolution of $\mathrm{OH}$

287 and $\mathrm{HO}_{2}$ was studied. $\mathrm{OH}$ and $\mathrm{HO}_{2}$ are primary markers of the radical pool, therefore the

288 reactivity was chosen for this analysis. The results of PRF60 and 2-MF (5\%, 10\%, and 20\%) are

289 compared with respective blends of ethanol, and toluene blended with PRF60 are presented in

290 Figs. 5-10. Two-stage ignition behavior is observed in all cases. The first-stage is the low- 
291 temperature heat release (LTHR), which marginally increases the temperature. Next, there was a 292 second-stage delay period before high-temperature reactions (HTHR) began, leading to faster 293 heat release. $\mathrm{OH}$ and $\mathrm{HO}_{2}$ mole fraction followed the heat release closely with local peaks 294 occurring in the LTC region. $n$-Heptane in the given plots exhibited substantial low-temperature 295 chemistry. Essentially, alkyl radicals undergo $\mathrm{O}_{2}$ addition at low temperatures, and peroxy 296 radical intramolecular isomerization and subsequent $\mathrm{O}_{2}$ additon leads to the formation of 297 ketohydroperoxides and other chain branching intermediates [61]. These highly oxygenated 298 molecules can dissociate to yield reactive $\mathrm{OH}$ radical leading to heat release. However, with an 299 increase in temperature, the pathway leading to low-temperature branching is no longer essential. 300 The $\mathrm{HO}_{2}$ radical abstracts $\mathrm{H}$ atom from the fuel, forming meta-stable $\mathrm{H}_{2} \mathrm{O}_{2}$, eventually 301 decomposing to $\mathrm{OH}$ radicals and leading to HTHR.

As expected, the total IDT increased from $0.02 \mathrm{sec}$ for PRF60 to $0.14 \mathrm{sec}$ for PRF60MF20, and 303 close to $0.03 \mathrm{sec}$ for both PRF60E20 and PRF60T20. The simulations, apart from capturing the 304 trend well, show that the increase in IDT is due to LTHR suppression by 2-MF addition, as 305 shown in Fig. 6. LTC suppression was confirmed by tracking $\mathrm{OH}$ and the $\mathrm{HO}_{2}$ radical pool. 306 Because of the reduced LTHR, the temperature increase at the end of LTHR was less than in the 307 case of PRF60. This delays the onset of high-temperature chemistry, and therefore, increases 308 ignition delay time.

309 Assuming that high-temperature reactions take place roughly at the same temperature, the delta T 310 between the temperature at the end of LTHR and onset of HTHR is directly proportional to a 311 mixture's resistance to its auto-ignition. Another noteworthy observation from Figs. 5-8 is that, 312 with increasing 2-MF fraction in the 2-MF/PRF60 blend, the second-stage ignition delay is 313 reduced. Previous research work focusing on fuel sensitivity reports a similar trend of shorter 
314 second-stage ignition delay and subsequent lower intermediate-temperature heat release with

315 increasing S value [32]. Relative to the total IDT, the second-stage IDT falls linearly with the

316 addition of 2-MF.

317 The similar magnitude of LTHR suppression, as well as second-stage IDT (more or less), is also

318 seen when toluene is the additive. The qualitative agreement with the observations made in IQT

319 and thereafter in KLSA tests, can also be observed. Fig. 9 summarises the observations in terms

320 of maximum peaks of heat release rate $(\mathrm{HRR}), \mathrm{OH}$, and $\mathrm{HO}_{2}$ with several mixtures. For

321 comparison, as a low-temperature chemistry-neutral molecule, iso-octane, was used. iso-Octane

322 addition to PRF60 would merely yield a higher PRF blend (PRF62 (5\%), PRF64 (10\%), PRF66

323 (15\%) and PRF68 (20\%) mixtures). As expected, LTHR decreases linearly with iso-octane

324 addition. Ethanol, which acts as a radical scavenger, suppressed the LTHR non-linearly and

325 reduced the reactivity more than with iso-octane addition, which can be seen by the reduction in

326 the radical pool of $\mathrm{OH}$ and $\mathrm{HO}_{2}$. With the addition of 2-MF, it was seen that LTHR suppression

327 was much stronger than either iso-octane or ethanol. This is achieved by suppressed reactivity, as

328 evident from the radical pool in Figs. 9 (b) and 9 (c).

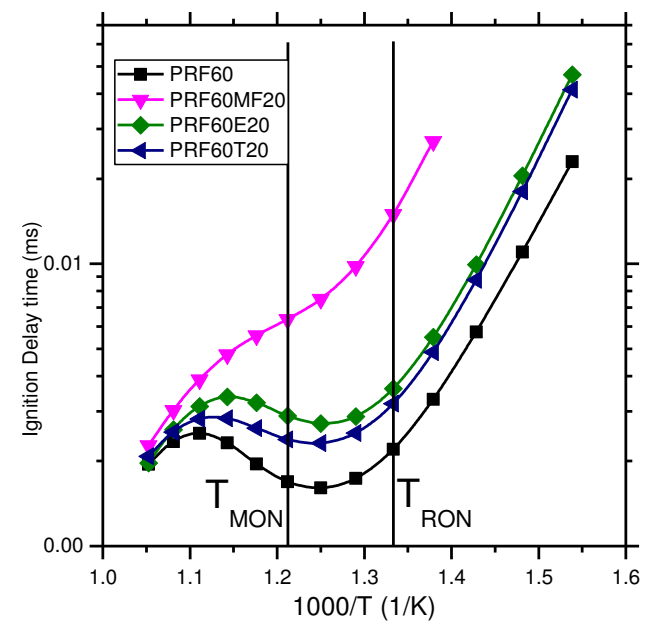


330 Figure 4: Simulated IDT in a batch reactor using CHEMKIN PRO for stoichiometric fuel/air mixtures.

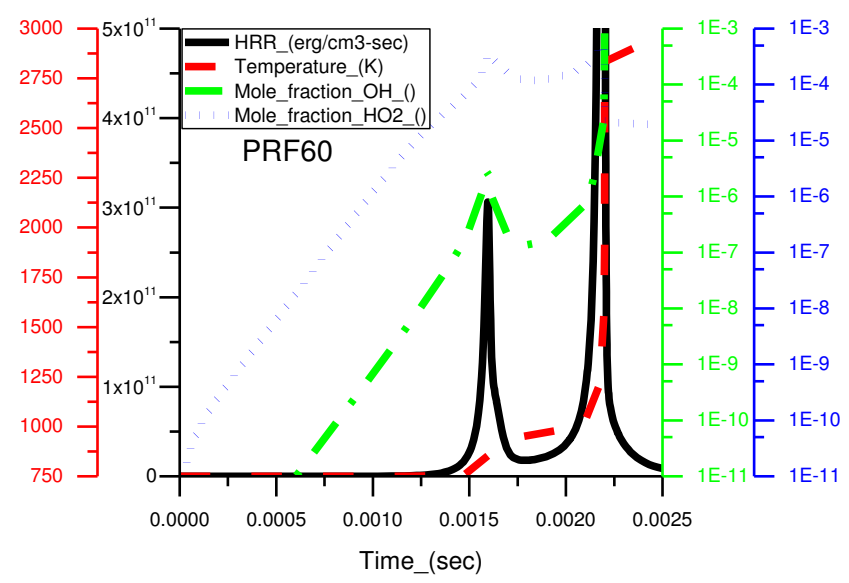

Figure 5: Time history of HRR, temperature, $\mathrm{OH}, \mathrm{HO}_{2}$ for PRF60 at $750 \mathrm{~K} 25 \mathrm{bar}$.

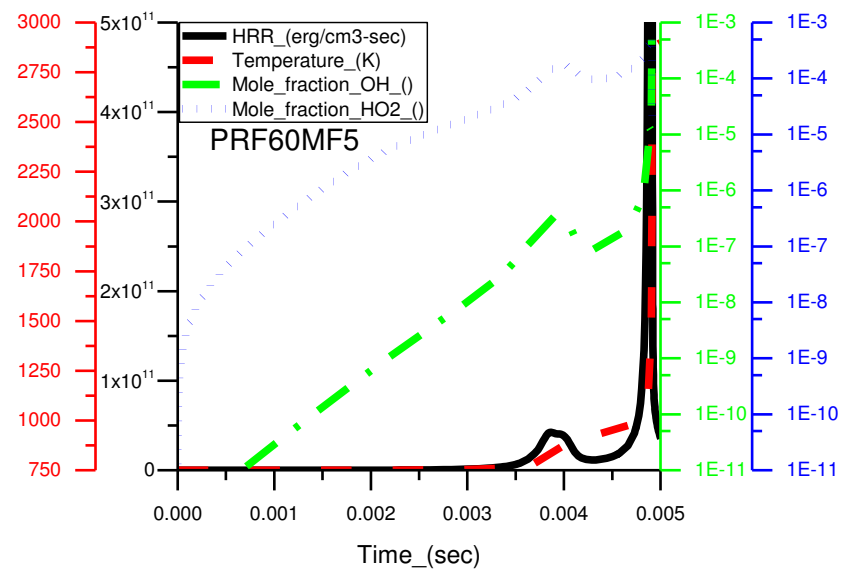



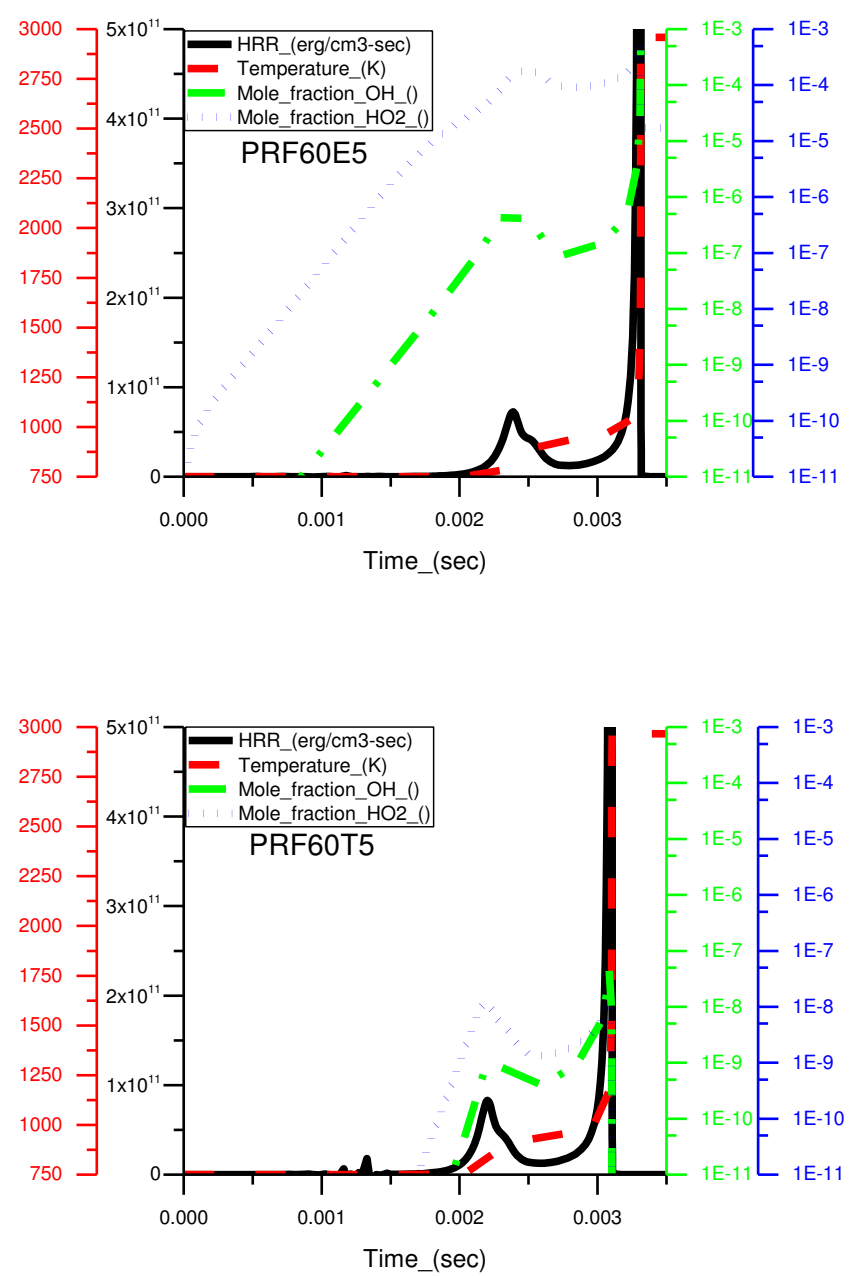

Figure 6: Time history of HRR, temperature, $\mathrm{OH}, \mathrm{HO}_{2}$ for (a) PRF60MF5, (b) PRF60E5 and (c)

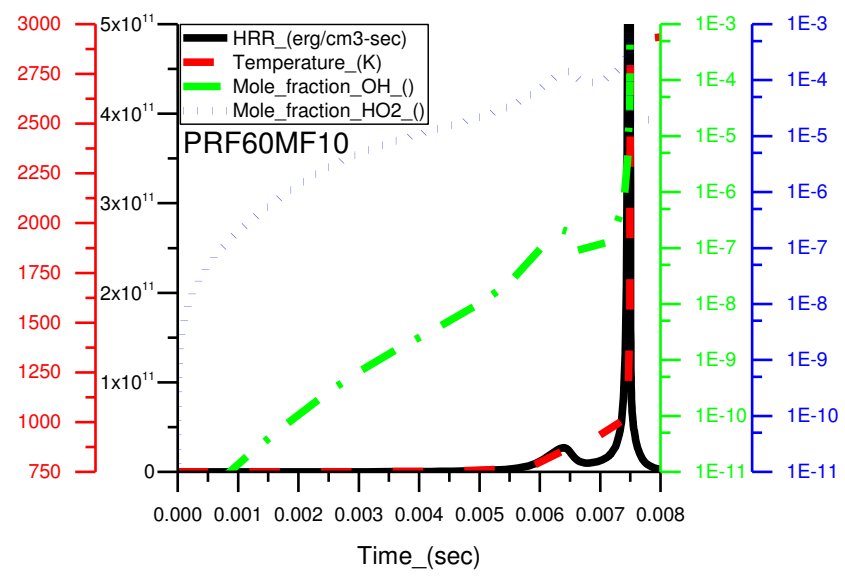



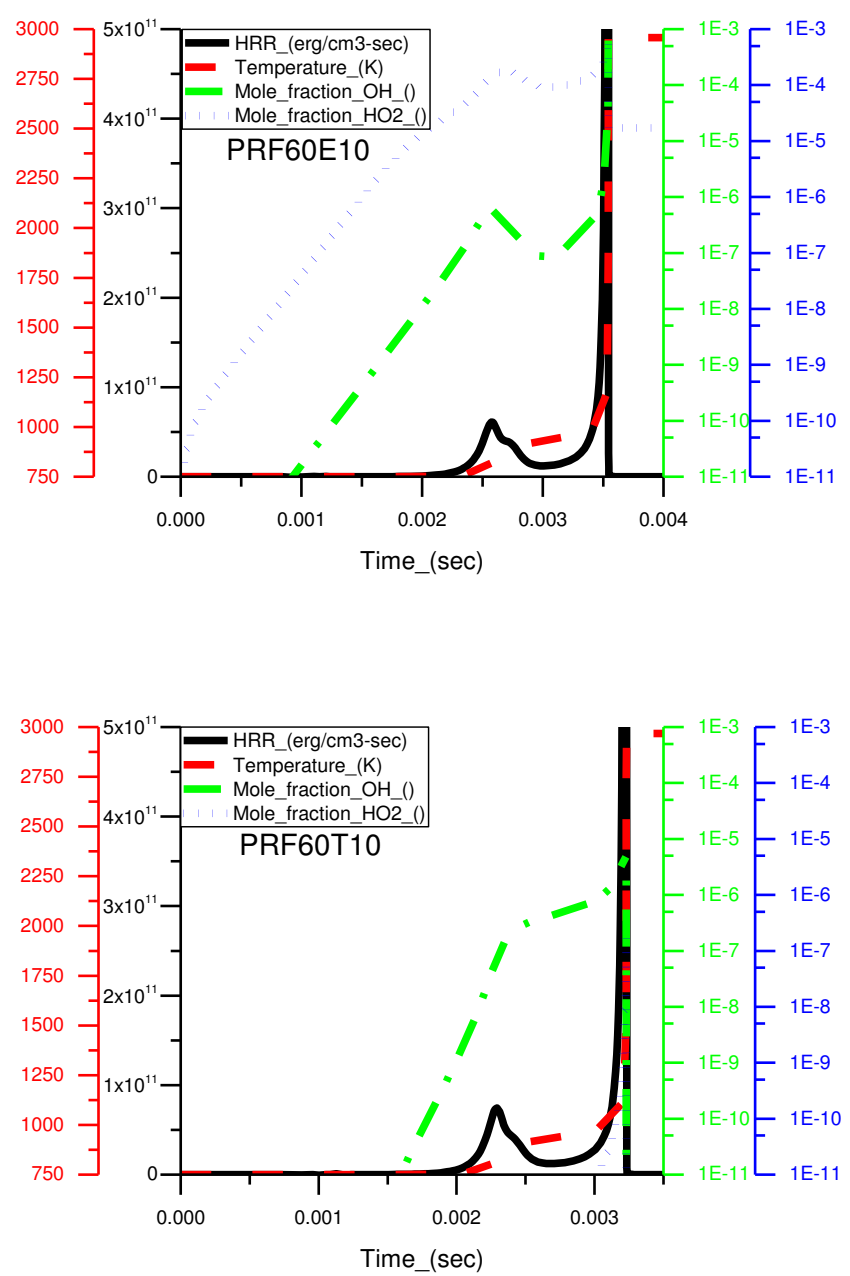

342 Figure 7: Time history of HRR, temperature, $\mathrm{OH}, \mathrm{HO}_{2}$ for (a) PRF60MF10, (b) PRF60E10 and (c) PRF60T10 at $750 \mathrm{~K} 25$ bar.

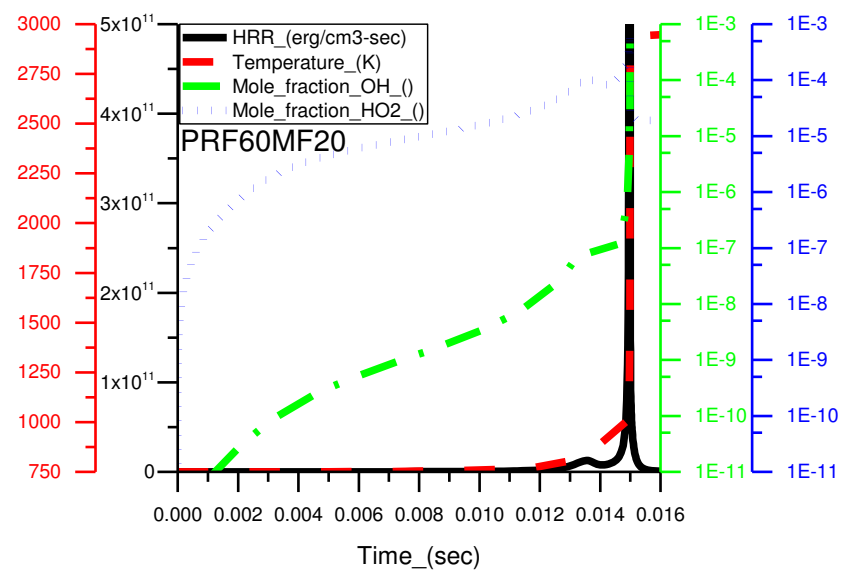



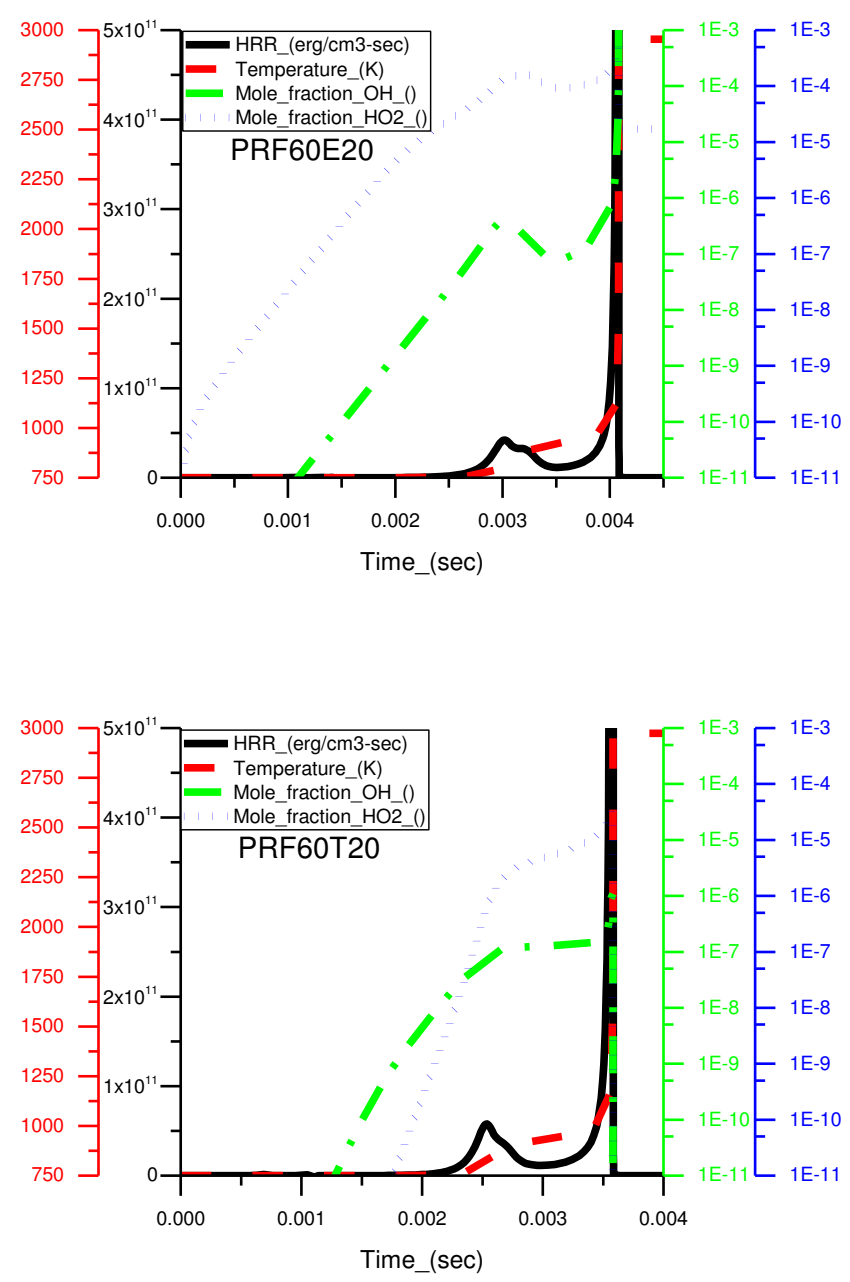

347 Figure 8: Time history of HRR, temperature, $\mathrm{OH}, \mathrm{HO}_{2}$ for (a) PRF60MF20, (b) PRF60E20 and
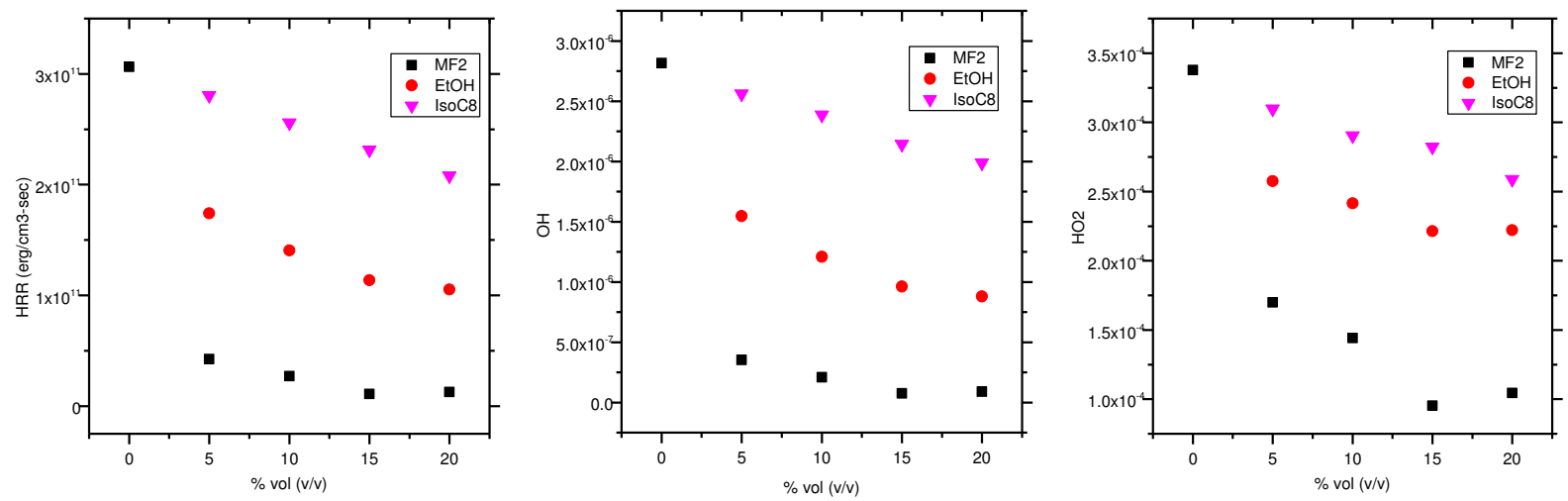
350 Figure 9: Maximum $\mathrm{HRR}(\mathrm{a}), \mathrm{OH}(\mathrm{b})$ and $\mathrm{HO}_{2}$ (c) in low-temperature region. Black (square

351 symbol) corresponds to 2-MF addition. Red (circle) corresponds to ethanol addition and pink

352 (triangle) corresponds to iso-octane addition in PRF60.

353

354

355

356

357

358

359

360

361

362

363

364

365

\section{HCCI experiments in CFR:}

To experimentally establish the efficacy of 2-MF addition on LTHR suppression (subsequently leading to improved knock behavior), a set of fuel blends were run in a CFR engine in HCCI mode. HCCI experiments often correlate well with the knocking tendency of the fuel, since knock is also an end-gas auto-ignition phenomenon, and HCCI is a combustion technology based on auto-ignition of complete charge. There are always greater disparities between the two phenomena, as auto-ignition ahead of the spark-ignited flame front also depends on the flame front propagation speed. However, in the past, the two have been correlated with good confidence. Correlations by Waqas et al. [57] have been improved herein, with the inclusion of PRF60 into the dataset, which changes the constant coefficients for obtaining the HCCI \#3. Details of the methodology are elaborated in [57]. The HCCI \# is related to the compression ratio, at which CA50 $\sim 3 \mathrm{CAD}$ after TDC is maintained for $\lambda=3$. By including PRF60 in the previous model, a second-order polynomial was found to be the best fit with $\mathrm{R}^{2}=0.9954$.

$$
H C C I \# 3=-0.1325(C R)^{2}+10.688(C R)-37.335
$$

where CR is the compression ratio at which CA50 of 3 CAD after TDC is achieved for $\lambda=3$.

Figure 10 shows experimental results. The compression ratios reached using 2-MF were much higher than in the case of ethanol; this is directly translated to a higher HCCI \#3, as shown in Fig. 10(b). PRF60MF20 shows HCCI \#3 close to 90, which corresponds to the behavior of PRF90. In comparison to ethanol, 2-MF was superior in every volumetric blend. The BON, as 
371 described in the methodology section, is also shown. 2-MF shows blending octane behavior

372 close to 208, as opposed to 146 shown for ethanol at $20 \%$ blend (v/v). In contrast to ethanol, the

373 BON of 2-MF continues to increase with the increasing blend ratio, a testament to the better

374 utilization of the fuel as a blending agent (rather than pure fuel, as previously suggested by

375 several authors).

376

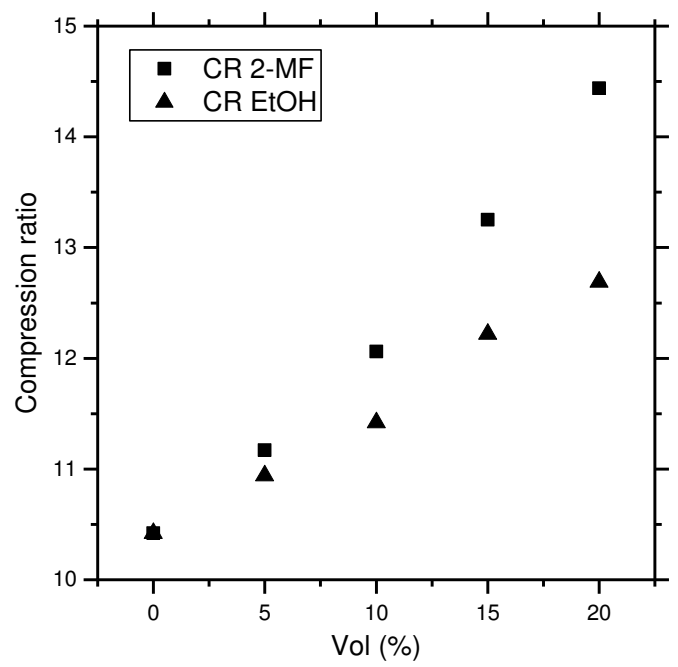

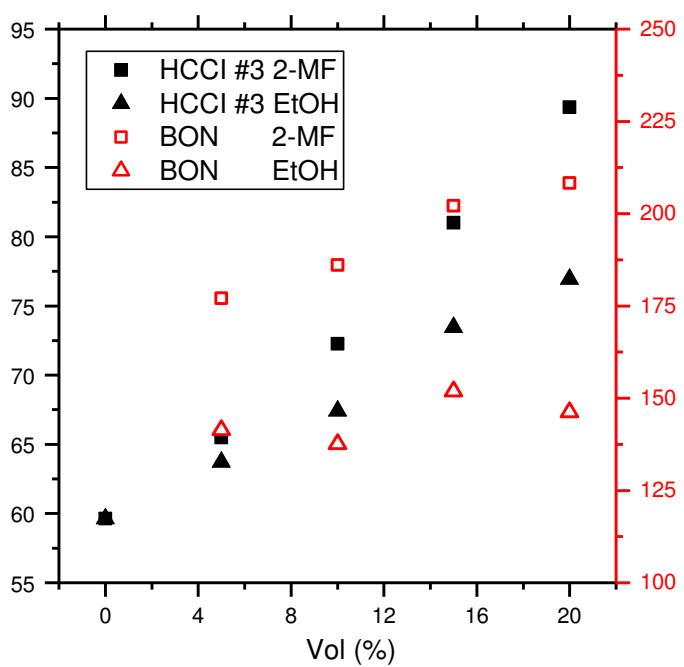

377 Figure 10: (a) CR for achieving CA50 3CAD aTDC (b) HCCI \#3 and BON for mixtures of 2-

378 MF (square) and ethanol (triangle) in PRF60. Left (black) axis is for HCCI \#3, shown in solid 379 black shapes. Right (red) axis for HCCI \#3, shown in hollow red shapes.

380 Heat release analysis of the HCCI experiments was performed on the basis of the methodology 381 described earlier and is shown in Fig. 11. By concentrating on the area of low temperature 382 chemistry, it becomes clear how heat release is suppressed with the addition of boosting agents. 383 The tests were also conducted using ethanol blended in PRF60, for comparison. These 384 observations experimentally confirmed that LTHR suppression by 2-MF is superior to ethanol. 385 At $20 \%$ volumetric blend, ethanol addition still shows some heat release, while the 2-MF 386 addition completely suppressed LTHR. At each point (5\%, 10\%, and 15\%), the LTHR 
magnitude with a 2-MF addition was lower than with the addition of ethanol. Being a lighter molecule, ethanol has a higher number of moles for similar volumetric blend compared to 2-MF. The mole fraction corresponding to the volume fractions appears in parenthesis in the legend. 390 This validates an even greater effectiveness of 2-MF on a mole basis. Furthermore, complete suppression of LTHR at $20 \%(\mathrm{v} / \mathrm{v})$ blend reinforces the fact that PRF60MF20 is the blend with 392 higher blending octane improvement behavior, established by the fact that 2-MF alone shows no 393 LTC in its pure state. If a low octane non-LTC blend (PRF60MF20 in this case) is combined 394 with a high-octane non-LTC fuel (pure 2-MF), the octane boosting tendency is close to linear 395 and the blending octane number goes down. This has been shown previously by the authors in an 396 example with ethanol [5]. Hence, the non-linear trend of octane boosting, by both ethanol and 2-

397 MF can be explained as follows: low temperature reactions lead to an increase in temperature, 398 subsequently accelerating the progress to high temperature reactions. When a radical scavenging 399 fuel is blended, it takes up the $\mathrm{HO}_{2}$ radicals formed in low temperature chemistry, thereby, 400 suppressing the reactivity and not allowing the temperature to increase. This further extends the 401 high temperature reactions too. Once the LTC is fully suppressed, the effect of octane booster 402 addition is merely replacing the low octane fuel with a high octane molecule, and hence linear. A 403 molecule showing stronger radical scavenging, and hence higher LTC suppression, should show 404 enhanced non-linearity in octane boosting tendency, up to the point of complete LTC 405 suppression. Additionally, it follows that full suppression of LTC can also be regarded as the 406 point of maximum gain from the octane boosting additive, which is shown to be lower for 2-MF 407 (20\% v/v in our study) compared to ethanol. 

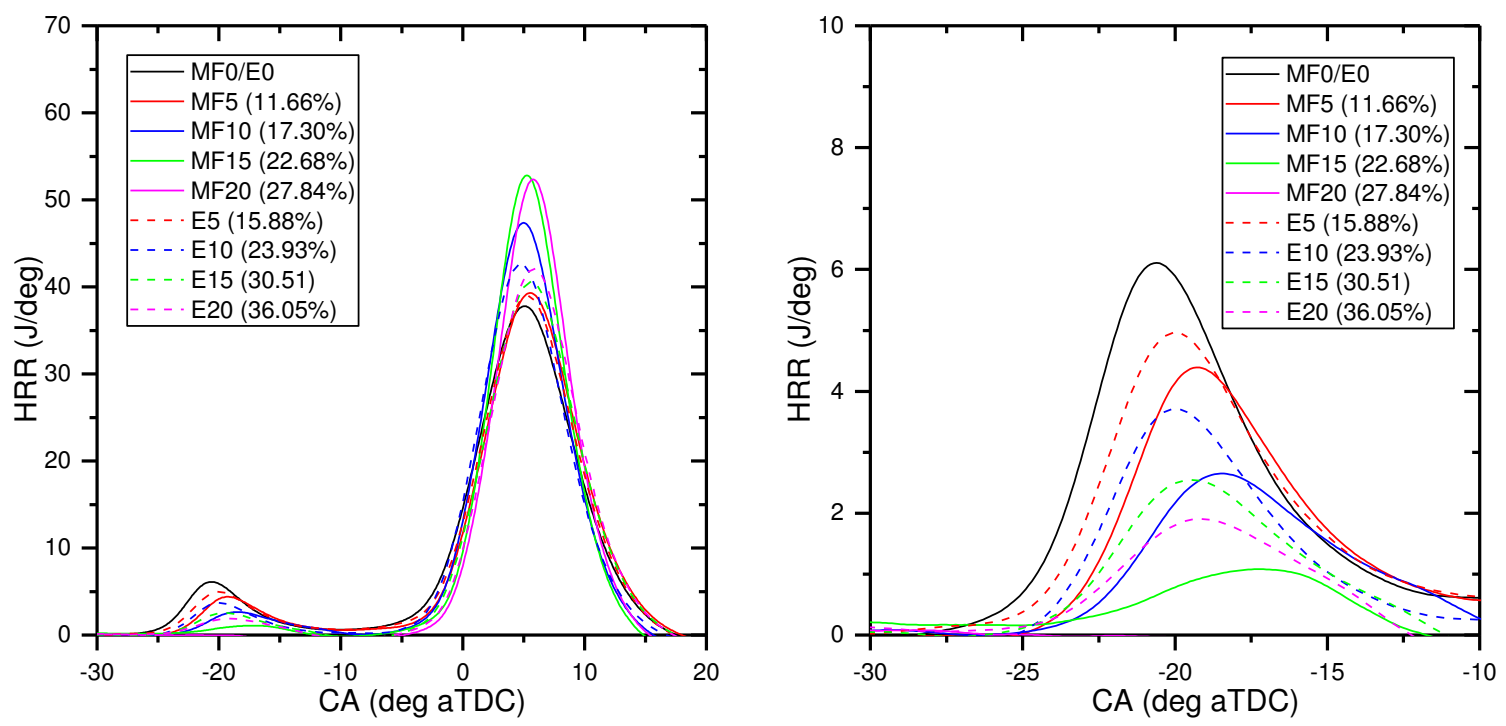

Figure 11: (a) Heat release rate (HRR) of various blends based on HCCI methodology (b) close

410 up of LTHR for the same case. (Mole fraction in brackets)

\section{Conclusion}

412 2-MF is a bio-derived compound that can be extracted from lignocellulosic biomass; it has

413 several advantages over other octane boosters. The physical properties and the energy density are

414 closer to gasoline, as opposed to ethanol. The intent of this work is to test the efficacy of the

415 compound as a knock suppressant.

416 Initial IQT tests provided promising results, showing very high blending octane numbers. Tests

417 on a modified CFR engine showed that $10 \%(\mathrm{v} / \mathrm{v})$ of 2-MF was more effective in mitigating

418 knock than even $20 \%$ (v/v) mixtures of toluene or ethanol in PRF60. Simulated ignition delay

419 times using a well-validated chemical kinetic mechanism in CHEMKIN PRO agreed with the

420 experimental observations. Further analysis investigated reactions leading to the suppression of

421 reactivity after adding octane boosting molecules. It was found that LTC suppression is

422 responsible for the highly effective nature of 2-MF as an octane booster. Engine experiments in 
423 HCCI mode showed very high BON of 208 with 20\% 2-MF addition to PRF60. Heat release

424 analysis of the experiments revealed that LTHR suppression using 2-MF is much higher at every

425 blend ratio than for the known radical scavenger, ethanol. On a mole basis, the effectiveness of

$426 \quad$ 2-MF only increases further.

427 This paper successfully demonstrates the use of 2-MF as a prospective octane booster. Factors

428 such as material compatibility and toxicity must be considered before it can be a viable option

429 for replacement or augmentation of ethanol, used ubiquitously as an octane booster. Moreover,

430 unlike previous work which focuses on the pure component, support is made for better utilization

431 of the fuel in lower volumetric blends. As the efficacy of 2-MF plateaus after 20\% (v/v) ratio;

432 this method also provides an opportunity for a more economic utilization for production of 2-

$433 \mathrm{MF}$, as well as for refiners. In conclusion, the benefits of 2-MF can be better realized as an

434 octane booster than as a pure fuel.

\section{Acknowledgements}

436 The authors gratefully acknowledge the support of this work from the Clean Combustion

437 Research Center (CCRC) at King Abdullah University of Science and Technology (KAUST).

438 The work at RWTH Aachen University was performed within the Cluster of Excellence "Tailor-

439 Made fuels from Biomass", which is funded by the Excellence Initiative by the German federal 440 and state governments to promote science and research at German universities.

$441 \quad$ References

442 [1] J. B. Heywood, Internal combustion engine fundamentals vol. 930: Mcgraw-hill New York, 1988.

443 [2] "Standard Test Method for Research Octane Number of Spark-Ignition Engine Fuel," Active

444

445

446 Standard ASTM D2699.

[3] "Standard Test Method for Motor Octane Number of Spark-Ignition Engine Fuel," Active Standard ASTM D2700 
[4] G. Edgar, "Measurement of knock characteristics of gasoline in terms of a standard fuel1," Industrial \& Engineering Chemistry, vol. 19, pp. 145-146, 1927.

449 [5] E. Singh, M. Waqas, B. Johansson, and M. Sarathy, "Simulating HCCl Blending Octane Number of Primary Reference Fuel with Ethanol," SAE Technical Paper 0148-7191, 2017.

[6] S. M. Sarathy, P. Oßwald, N. Hansen, and K. Kohse-Höinghaus, "Alcohol combustion chemistry," Progress in energy and Combustion Science, vol. 44, pp. 40-102, 2014.

[7] D. Pimentel and T. W. Patzek, "Ethanol production using corn, switchgrass, and wood; biodiesel production using soybean and sunflower," Natural resources research, vol. 14, pp. 65-76, 2005.

[8] T. Searchinger, R. Heimlich, R. A. Houghton, F. Dong, A. Elobeid, J. Fabiosa, et al., "Use of US croplands for biofuels increases greenhouse gases through emissions from land-use change," Science, vol. 319, pp. 1238-1240, 2008.

[9] J. Fargione, J. Hill, D. Tilman, S. Polasky, and P. Hawthorne, "Land clearing and the biofuel carbon debt," Science, vol. 319, pp. 1235-1238, 2008.

[10] R. L. McCormick, M. A. Ratcliff, E. Christensen, L. Fouts, J. Luecke, G. M. Chupka, et al., "Properties of oxygenates found in upgraded biomass pyrolysis oil as components of spark and compression ignition engine fuels," Energy \& Fuels, vol. 29, pp. 2453-2461, 2015.

[11] M. K. Shukla, E. Singh, N. Singh, and S. Singal, "Prospects of 2, 5-dimethylfuran as a fuel: physicochemical and engine performance characteristics evaluation," Journal of Material Cycles and Waste Management, vol. 17, pp. 459-464, 2015.

[12] S. Zhong, R. Daniel, H. Xu, J. Zhang, D. Turner, M. L. Wyszynski, et al., "Combustion and emissions of 2, 5-dimethylfuran in a direct-injection spark-ignition engine," Energy \& Fuels, vol. 24, pp. 2891-2899, 2010.

[13] R. Daniel, G. Tian, H. Xu, M. L. Wyszynski, X. Wu, and Z. Huang, "Effect of spark timing and load on a DISI engine fuelled with 2, 5-dimethylfuran," Fuel, vol. 90, pp. 449-458, 2011.

[14] C. Wang, H. Xu, R. Daniel, A. Ghafourian, J. M. Herreros, S. Shuai, et al., "Combustion characteristics and emissions of 2-methylfuran compared to 2, 5-dimethylfuran, gasoline and ethanol in a DISI engine," Fuel, vol. 103, pp. 200-211, 2013.

[15] L. R. JA DUMESIC, JN CHHEDA, "Catalytic process for producing furan derivatives from carbohydrates in a biphasic reactor," USA Patent, 2007.

[16] Y. Román-Leshkov, C. J. Barrett, Z. Y. Liu, and J. A. Dumesic, "Production of dimethylfuran for liquid fuels from biomass-derived carbohydrates," Nature, vol. 447, pp. 982-985, 2007.

[17] H. Zhao, J. E. Holladay, H. Brown, and Z. C. Zhang, "Metal chlorides in ionic liquid solvents convert sugars to 5-hydroxymethylfurfural," Science, vol. 316, pp. 1597-1600, 2007.

[18] D. A. Rothamer and J. H. Jennings, "Study of the knocking propensity of 2, 5-dimethylfurangasoline and ethanol-gasoline blends," Fuel, vol. 98, pp. 203-212, 2012.

[19] J. P. Lange, E. van der Heide, J. van Buijtenen, and R. Price, "Furfural-a promising platform for lignocellulosic biofuels," ChemSusChem, vol. 5, pp. 150-166, 2012.

[20] M. Thewes, M. Muether, S. Pischinger, M. Budde, A. Brunn, A. Sehr, et al., "Analysis of the impact of 2-methylfuran on mixture formation and combustion in a direct-injection sparkignition engine," Energy \& Fuels, vol. 25, pp. 5549-5561, 2011.

[21] M. Mehl, W. J. Pitz, C. K. Westbrook, and H. J. Curran, "Kinetic modeling of gasoline surrogate components and mixtures under engine conditions," Proceedings of the Combustion Institute, vol. 33, pp. 193-200, 2011.

[22] G. Tian, H. Xu, and R. Daniel, DMF-a new biofuel candidate: InTech, 2011.

[23] X. Ma, C. Jiang, H. Xu, H. Ding, and S. Shuai, "Laminar burning characteristics of 2-methylfuran and isooctane blend fuels," Fuel, vol. 116, pp. 281-291, 2014.

[24] http://www.ngk-sparkplugs.jp/english/techinfo/troubleshooting/04/. 
[25] G. T. Kalghatgi, "Auto-ignition quality of practical fuels and implications for fuel requirements of future SI and $\mathrm{HCCl}$ engines," SAE Technical Paper 0148-7191, 2005.

[26] G. Kalghatgi, "Fuel anti-knock quality-Part I. Engine studies," SAE Technical Paper 0148-7191, 2001.

[27] G. T. Kalghatgi, "Fuel anti-knock quality-Part II. Vehicle Studies-how relevant is Motor Octane Number (MON) in modern engines?," SAE Technical Paper 0148-7191, 2001.

[28] V. Mittal and J. B. Heywood, "The relevance of fuel RON and MON to knock onset in modern SI engines," SAE Technical Paper 0148-7191, 2008.

501

502

503

[29] W. R. Leppard, "The chemical origin of fuel octane sensitivity," SAE Technical Paper 0148-7191, 1990.

504

505

506

507

[30] A. Bell, "Modern SI engine control parameter responses and altitude effects with fuels of varying octane sensitivity," SAE Technical Paper 0148-7191, 2010.

[31] R. Cracknell, J. C. Andrae, L. McAllister, M. Norton, and H. Walmsley, "The chemical origin of octane sensitivity in gasoline fuels containing nitroalkanes," Combustion and Flame, vol. 156, pp. 1046-1052, 2009.

[32] E. Singh, J. Badra, M. Mehl, and S. M. Sarathy, "Chemical Kinetic Insights into the Octane Number and Octane Sensitivity of Gasoline Surrogate Mixtures," Energy \& Fuels, vol. 31, pp. 1945-1960, 2017.

[33] A. F. S.M. Sarathy, G.T. Kalghatgi. , "Recent progress in gasoline surrogate fuels.," Progress in Energy and Combustion Science., pp. 1-42, 2017.

[34] V. S. B. Shankar, M. Al-Abbad, M. El-Rachidi, S. Y. Mohamed, E. Singh, Z. Wang, et al., "Antiknock quality and ignition kinetics of 2-phenylethanol, a novel lignocellulosic octane booster," Proceedings of the Combustion Institute, vol. 36, pp. 3515-3522, 2017.

[35] M. Al-Khodaier, V. S. B. Shankar, M. Waqas, N. Naser, M. Sarathy, and B. Johansson, "Evaluation of Anti-Knock Quality of Dicyclopentadiene-Gasoline Blends," SAE Technical Paper 0148-7191, 2017.

[36] W. G. Lovell, "Knocking characteristics of hydrocarbons," Industrial \& Engineering Chemistry, vol. 40, pp. 2388-2438, 1948.

[37] I. Tiunov, M. Kotelev, V. Vinokurov, P. Gushchin, M. Bardin, and A. Novikov, "Antiknock Properties of Blends of 2-Methylfuran and 2, 5-Dimethylfuran with Reference Fuel," Chemistry and Technology of Fuels and Oils, pp. 1-7.

[38] U. B. R. Tripathi, C. Lee, A.C. Davis, L. Cai, A.K. Ramalingam, H. Selim, K.A. Heufer, R.X. Fernandes, H. Pitsch, S.M. Sarathy, "Oxidation of 2-methylfuran and 2-methylfuran/n-heptane blends: An experimental and modeling study.," in preperation, 2017.

[39] S. Y. Yang, N. Naser, S. H. Chung, and J. Cha, "Effect of Temperature, Pressure and Equivalence Ratio on Ignition Delay in Ignition Quality Tester (IQT): Diesel, n-Heptane, and iso-Octane Fuels under Low Temperature Conditions," SAE International Journal of Fuels and Lubricants, vol. 8, pp. 537-548, 2015.

[40] A. D6890, "Standard Test Method for Determination of Ignition Delay and Derived Cetane Number (DCN) of Diesel Fuel Oils by Combustion in a Constant Volume Chamber," ed.

[41] N. Naser, S. Y. Yang, G. Kalghatgi, and S. H. Chung, "Relating the octane numbers of fuels to ignition delay times measured in an ignition quality tester (IQT)," Fuel, vol. 187, pp. 117-127, 2017.

[42] N. Atef, G. Kukkadapu, S. Y. Mohamed, M. Al Rashidi, C. Banyon, M. Mehl, et al., "A comprehensive iso-octane combustion model with improved thermochemistry and chemical kinetics," Combustion and Flame, vol. 178, pp. 111-134, 2017. 
[43] K. P. Somers, J. M. Simmie, F. Gillespie, C. Conroy, G. Black, W. K. Metcalfe, et al., "A comprehensive experimental and detailed chemical kinetic modelling study of 2, 5-

[44] K. P. Somers, J. M. Simmie, W. K. Metcalfe, and H. J. Curran, "The pyrolysis of 2-methylfuran: a quantum chemical, statistical rate theory and kinetic modelling study," Physical Chemistry Chemical Physics, vol. 16, pp. 5349-5367, 2014.

[45] A. C. Davis and S. M. Sarathy, "Computational study of the combustion and atmospheric decomposition of 2-methylfuran," The Journal of Physical Chemistry A, vol. 117, pp. 7670-7685, 2013.

[46] R. Design, "CHEMKIN-PRO," ed: Reaction Design San Diego, CA, 2008.

[47] P. Ghosh, K. J. Hickey, and S. B. Jaffe, "Development of a detailed gasoline composition-based octane model," Industrial \& engineering chemistry research, vol. 45, pp. 337-345, 2006.

[48] H. J. Lugo, G. Ragone, and J. Zambrano, "Correlations between octane numbers and catalytic cracking naphtha composition," Industrial \& engineering chemistry research, vol. 38, pp. 21712176, 1999.

[49] S. Park, O. Mannaa, F. Khaled, R. Bougacha, M. S. Mansour, A. Farooq, et al., "A comprehensive experimental and modeling study of 2-methylbutanol combustion," Combustion and Flame, vol. 162, pp. 2166-2176, 2015.

[50] S. M. Sarathy, C. K. Westbrook, M. Mehl, W. J. Pitz, C. Togbe, P. Dagaut, et al., "Comprehensive chemical kinetic modeling of the oxidation of 2-methylalkanes from C 7 to C 20," Combustion and flame, vol. 158, pp. 2338-2357, 2011.

[51] S. M. Sarathy, T. Javed, F. Karsenty, A. Heufer, W. Wang, S. Park, et al., "A comprehensive combustion chemistry study of 2, 5-dimethylhexane," Combustion and Flame, vol. 161, pp. 1444-1459, 2014.

[52] W. Wang, Z. Li, M. A. Oehlschlaeger, D. Healy, H. J. Curran, S. M. Sarathy, et al., "An experimental and modeling study of the autoignition of 3-methylheptane," Proceedings of the Combustion Institute, vol. 34, pp. 335-343, 2013.

[53] M. Mehl, J.-Y. Chen, W. J. Pitz, S. M. Sarathy, and C. K. Westbrook, "An approach for formulating surrogates for gasoline with application toward a reduced surrogate mechanism for CFD engine modeling," Energy \& Fuels, vol. 25, pp. 5215-5223, 2011.

[54] M. Mehl, T. Faravelli, F. Giavazzi, E. Ranzi, P. Scorletti, A. Tardani, et al., "Detailed chemistry promotes understanding of octane numbers and gasoline sensitivity," Energy \& fuels, vol. 20, pp. 2391-2398, 2006.

[55] N. Naser, S. M. Sarathy, and S. H. Chung, "Estimating fuel octane numbers from homogeneous gas-phase ignition delay times," Combustion and Flame, vol. 188, pp. 307-323, 2018.

[56] I. Truedsson, W. Cannella, B. Johansson, and M. Tuner, "Development of new test method for evaluating $\mathrm{HCCl}$ fuel performance," SAE Technical Paper 0148-7191, 2014.

[57] M. Waqas, N. Naser, M. Sarathy, K. Morganti, K. Al-Qurashi, and B. Johansson, "Blending Octane Number of Ethanol in $\mathrm{HCCl}, \mathrm{SI}$ and $\mathrm{Cl}$ Combustion Modes," SAE International Journal of Fuels and Lubricants, vol. 9, pp. 659-682, 2016.

[58] T. M. Foong, K. J. Morganti, M. J. Brear, G. da Silva, Y. Yang, and F. L. Dryer, "The octane numbers of ethanol blended with gasoline and its surrogates," Fuel, vol. 115, pp. 727-739, 2014.

[59] J. Griffiths, P. Halford-Maw, and C. Mohamed, "Spontaneous ignition delays as a diagnostic of the propensity of alkanes to cause engine knock," Combustion and flame, vol. 111, pp. 327-337, 1997.

[60] J. A. Badra, N. Bokhumseen, N. Mulla, S. M. Sarathy, A. Farooq, G. Kalghatgi, et al., "A methodology to relate octane numbers of binary and ternary $n$-heptane, iso-octane and toluene mixtures with simulated ignition delay times," Fuel, vol. 160, pp. 458-469, 2015. 
[61] E.-A. Tingas, Z. Wang, S. M. Sarathy, H. G. Im, and D. A. Goussis, "Chemical kinetic insights into the ignition dynamics of n-hexane," Combustion and Flame, vol. 188, pp. 28-40, 2018.

590 
Supplementary Material
Click here to download Supplementary Material: Supplementary Material.docx

Supplementary Material
Click here to download Supplementary Material: Supplementary Material.docx

\begin{abstract}
click here to download Supplementary Material: Supplementary Materialdocx
\end{abstract}

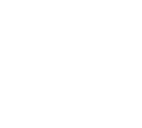

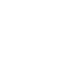

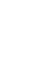

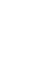

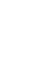

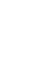

.

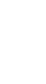

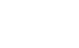

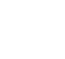

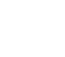

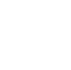

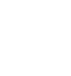

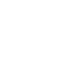

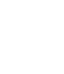

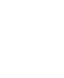

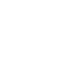

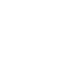

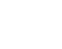

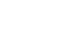

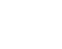

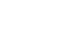

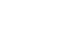

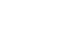

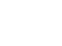

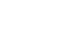

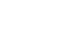

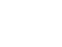

